\title{
Systematic screening of isogenic cancer cells identifies DUSP6 as context-specific synthetic lethal target in melanoma
}

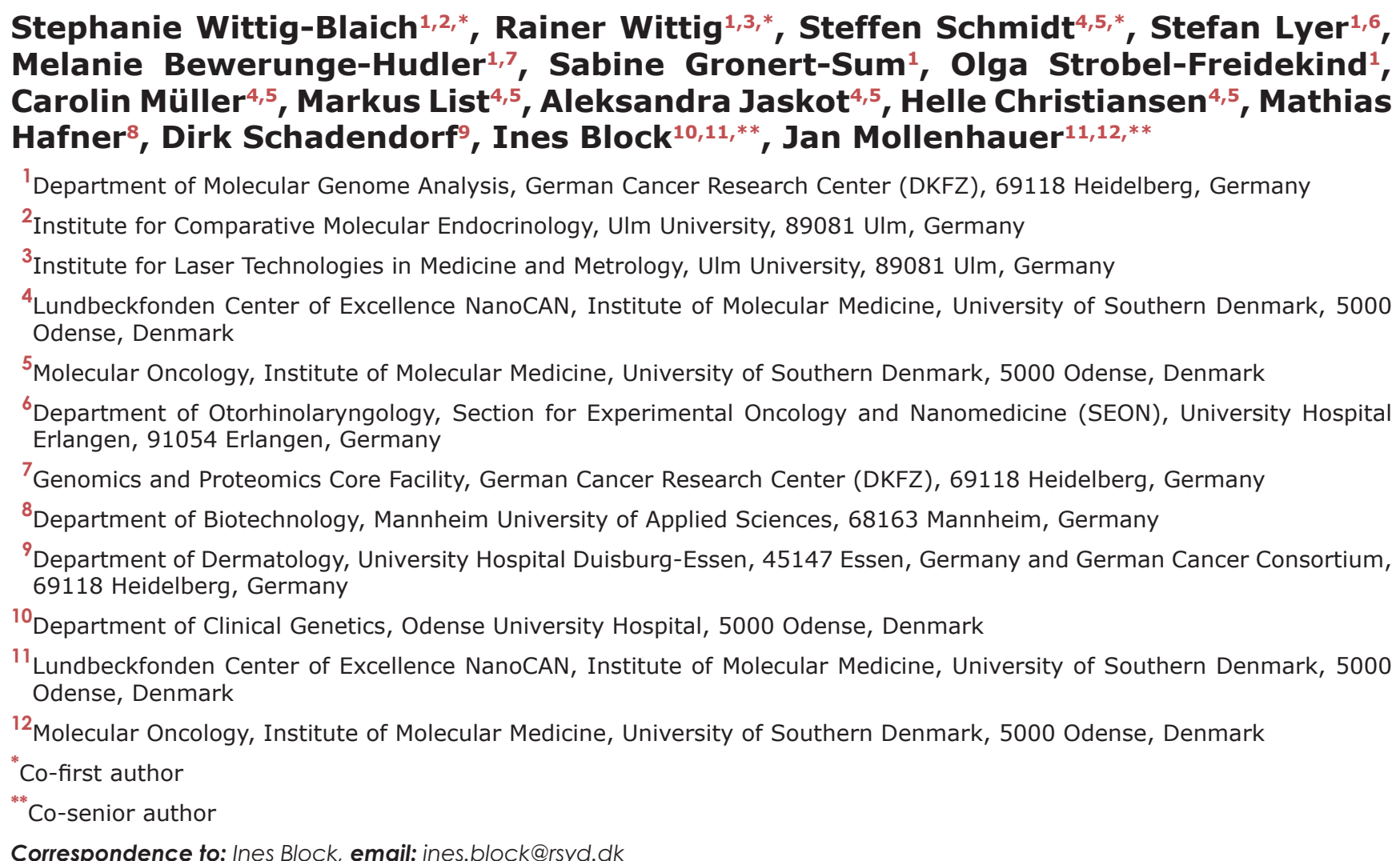

Keywords: cancer, isogenic cell line libraries, functional genomics, melanoma, synthetic lethal

Received: September 14,2016 Accepted: February 06, $2017 \quad$ Published: March 02, 2017

\section{ABSTRACT}

Next-generation sequencing has dramatically increased genome-wide profiling options and conceptually initiates the possibility for personalized cancer therapy. State-of-the-art sequencing studies yield large candidate gene sets comprising dozens or hundreds of mutated genes. However, few technologies are available for the systematic downstream evaluation of these results to identify novel starting points of future cancer therapies.

We improved and extended a site-specific recombination-based system for systematic analysis of the individual functions of a large number of candidate genes. This was facilitated by a novel system for the construction of isogenic constitutive and inducible gain- and loss-of-function cell lines. Additionally, we demonstrate the construction of isogenic cell lines with combinations of the traits for advanced functional in vitro analyses. In a proof-of-concept experiment, a library of 108 isogenic melanoma cell lines was constructed and 8 genes were identified that significantly reduced viability in a discovery screen and in an independent validation screen. Here, we demonstrate the broad applicability of this recombination-based method and we 


\section{proved its potential to identify new drug targets via the identification of the tumor suppressor DUSP6 as potential synthetic lethal target in melanoma cell lines with BRAF V600E mutations and high DUSP6 expression.}

\section{INTRODUCTION}

Since its advent, genome-wide mRNA expression profiling has been extensively used to compare tumors versus normal tissues, different stages of cancer progression, expression patterns associated with drug resistance and differences between cancer subtypes. In recent years, next-generation sequencing (NGS) techniques have further enabled researchers to sequence DNA and mRNA for mutations on genome-wide scale. Commonly, these approaches discover several hundreds of genes with recurrent mutations.

The first consensus mutational map generated using NGS identified 189 genes with potentially relevant mutations in driver genes of breast and colon cancer, most of which have an unknown role in cancer [1,2]. Shah et al. recently identified more than 2,000 somatic single nucleotide variations including 107 insertion-deletion mutations in triple negative breast cancer [3]. In addition, four studies identified a cumulated set of 137 genes with potential driver mutations in melanoma [4-7]. Elucidating these genes' functions and interplay is a critical step towards the identification of novel starting points for therapy as, for example, demonstrated by the development of PARP-inhibitors for BRCA1/2-deficient tumors [8].

To translate the results of mutation screens into clinical applications, in-depth characterization of the phenotypic effect of each mutation is essential. However, systematic downstream functional analysis is rarely considered and evaluation commonly limited to a single or few genes [1-7]. The lack of comprehensive functional approaches may partially be due to limitations of existing strategies. Conceptually, lentiviral systems may enable functional studies of large gene sets as they enable efficient stable genomic insertion even in non-dividing cells [9]. A major drawback of this method is that multiple insertions may occur in a cell, leading to unaccounted copynumber variation effects. Moreover, the random genomic integration may create a highly heterogeneous population.

Alternatives that overcome these limitations of lentiviral systems are genome-editing techniques based on, for example, zinc finger nucleases, CRISPR/Cas9 or Transcription Activator-Like Effector Nucleases (TALENs). They enable targeted insertion of genetic changes with high precision at single nucleotide-level. In contrast to lentiviral systems, genome editing allows for the creation of isogenic cells which differ only in the introduced genetic alteration. However, the efficacy of these techniques is variable and often in the lower percent range [10-14].

Site-specific recombination-based systems, such as the Flp-FRT [15] and the Cre-lox system [16], facilitate stable insertion of a recombinase recognition sequence
(FRT- or lox-site) into the host cell genome. These sequences can consecutively be used to insert genes into the prepared chromosomal site, allowing for the derivation of isogenic cell lines with high efficacy.

Due to the high degree of standardization, we expected this technique to be suitable for serially analyzing large gene sets. First, we optimized an existing site-specific recombination-based system for the rapid and effective construction of isogenic cell line panels. Second, we extended this system to simplify cell line construction with either constitutive or inducible expression of a single gene or two genes of interest. Subsequently, we demonstrated the successful recombination at a single genomic location in a number of cell lines of different cancer types. We then selected one of these cell lines, A375, as a representative for a proof-of-concept screen, in which we constructed more than a hundred isogenic melanoma cell lines. An independent repetition of the cell line construction procedure was conducted for a subset of these genes to demonstrate the reproducibility of the results. Finally, the top five growth-suppressing genes were further characterized by cell cycle analysis and by generating cell line recombinants for cell lines of other cancer types. A main finding of additional proofof-concept experiments was that the tumor suppressor DUSP6 could serve as a potential synthetic lethal drug target in melanoma with BRAF V600E mutations.

\section{RESULTS}

\section{Re-design of site-specific recombination systems}

Site-specific recombination has been used for various applications, such as, an endogenous sequence of the host cell genome used for the insertion of sequences of interest (e.g. the rosa locus in mice) [17]. Moreover, exogenous sequences like FRT- or lox-sites can be stably integrated for subsequent gene insertion [15-17]. Remarkably, these techniques have been used extensively for generating transgenic mice, but have not been exploited for in vitro functional genomics approaches.

We initially used the commercially available FlpIn system (Life Technologies). The system provides a plasmid (pFRT/lacZeo) to first insert the FRT recombination site into the host cell genome. The FRTsite locates between a cytomegalovirus (CMV) promoter with an ATG start codon that drives expression of a lacZ-zeocin resistance fusion gene. Our goal was to insert an expression plasmid hosting a gene of interest as well as a hygromycin resistance gene using the Flp recombinase. The inserted genes would be under the control of the CMV promoter and start codon, thereby 
eliminating the expression of the zeocin resistance fusion gene. Accordingly, the absence of lacZ positive and zeocin resistant cells, and the presence of hygromycin resistance would indicate successful transfections. As no correspondingly modified cancer cell lines are available, we transfected the frequently used cancer cell lines A375 (melanoma), MCF7 (breast cancer), U251-MG (brain cancer), and A549 (lung cancer). Unfortunately, repeated transfections with the pFRT/lacZeo plasmid yielded low numbers of lacZ-positive cells in three of the four cell lines (Figure 1). Moreover, attempts to generate stable isogenic cell lines via site-specific recombination did not result in any hygromycin-resistant cells (data not shown).

We therefore created new vectors in which the ATGFRT cassette was placed upstream of an EGFP reporter using pEGFP-N1 (Clontech) as the backbone (Figure 2A, Supplementary Figure 1 and Supplementary Table 1). This configuration substituted the lacZ-zeocin resistance fusion gene with EGFP and a separate, i.e. non-fused, neomycin resistance gene. One vector variant (pRAPacc1) was equipped with the CMV promoter, while the other (pRAPacc2) contained the elongation factor 1-alpha $(\mathrm{E} 1 \mathrm{~F} \alpha)$ promoter. Using these newly generated vectors, reporter-positive cells were generated with 15- to 188-fold increased efficacy compared to the original system and, in addition, stably transfected clones of A549 cells were obtained which was not achieved with the pFRT/lacZeo system (Figure 1).

We further modified the expression plasmids (referred to as pRAPtar vectors) to enable serial construction of cell lines with constitutive and inducible expression of single or multiple genes. The pRAPtar-1c was designed for constitutive expression of target genes, while pRAPtar- $1 \mathrm{i}$ contained a doxycycline (dox)-inducible promoter and a Tet-repressor in cis to provide isogenic cells with inducible expression in a single recombination step (Figure 2A and 2B, Supplementary Figure 1). The latter is particularly useful when studying cancer-related genes, since their constitutive expression often causes increased cell death.

In addition to the recombination-activated hygromycin resistance gene, we inserted a lox71-site [16] preceded by an SV40 promoter and an ATG start codon. As a result, the introduction of the first plasmid established a secondary recombination site suitable for the insertion of a plasmid via Cre-lox-mediated recombination. Consequently, a constitutive (pRAPtar-2c) and an inducible version (pRAPtar-2i) of the corresponding expression vector were generated. These carried a lox66-site preceding a startcodon-deficient puromycin resistance gene (Figure 2A, Supplementary Figure 1). Thus, successful Cre-mediated recombination yielded puromycin-selectable cells. Finally, the pRAPtar-2 vectors further contain a third recombination site (phiC31 attP site) [18] to theoretically allow for the consecutive insertion of another sequence (Figure 2B, Supplementary Figure 1).

Accordingly, following stable insertion of the pRAPacc vectors to provide a so-called acceptor cell line (ACL), the system allows for constructing isogenic single recombinant cells (ISRs) via Flp-recombinase that have constitutive or inducible expression of a target sequence. Depending on whether a gene or a knockdown construct

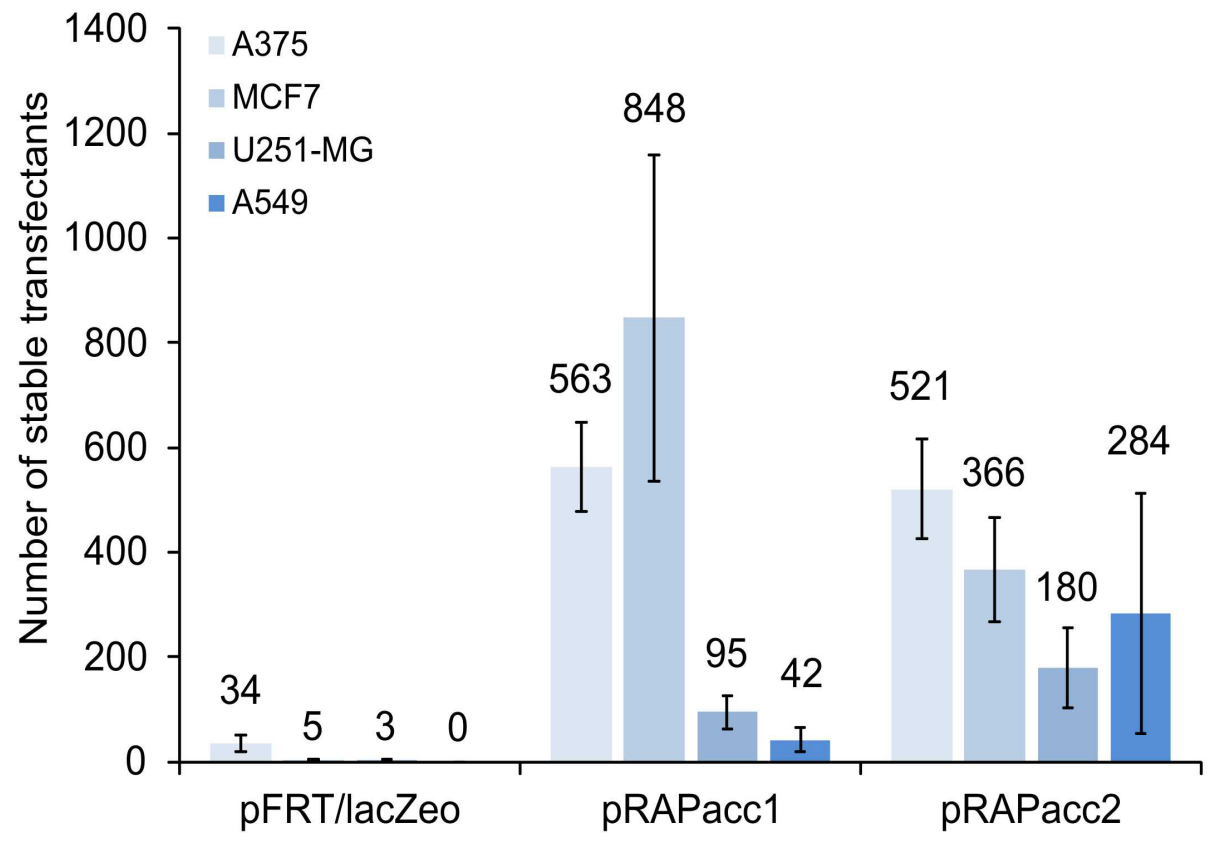

Figure 1: Vector performance in generating FRT-site modified acceptor cell lines. Four cancer cell lines were transfected under identical conditions with either pFRT/lacZeo from the commercially available Flp-In system or with pRAPacc1 or 2 . After two weeks of selection, the number of lacZ-positive (pFRT/lacZeo) and of EGFP-positive cells (pRAPacc1/2) was scored. Values are averages of at least two independent experiments. Error bars represent standard error of the mean (SEM). 
(e.g. shRNA or pri-miRNA) is inserted, this results in a cell line for subsequent gain- or loss-of-function studies (Figure 2B). Consecutively, ISRs can be used to insert a second sequence expressed in a constitutive or inducible fashion to obtain isogenic double recombinant cells (IDRs) with combinatorial traits (Figure 2B).

\section{Construction of acceptor cell lines}

We next constructed a panel of ACLs from 10 commonly used cell lines of various cancer types (Table 1). After transfection of pRAPacc vectors and selection of neomycin-resistant clones, we processed 16-54 stable EGFP-positive clones per cell line to identify cell lines suitable as ACLs for further studies.
We expected that some clones would host multiple insertions of vectors into the cell's genome, compromising subsequent selection of positive recombinants and conceivably favoring undesired intra- or interchromosomal recombination events. Thus, we tested an initial set of 374 individual clones for single integration via Southern blotting, yielding 70 clones (19\%), for which single integration could be confirmed (Table 1, Supplementary Figure 2).

Next, the ability to accept an expression plasmid via Flp-mediated recombination was assessed, using the red fluorescent HcRed reporter gene cloned into pRAPtar1c. Most, but not all, of the clones (50 out of 70; 71\%) readily delivered stable hygromycin-resistant ISRs, in which EGFP was switched off and the HcRed gene was

A
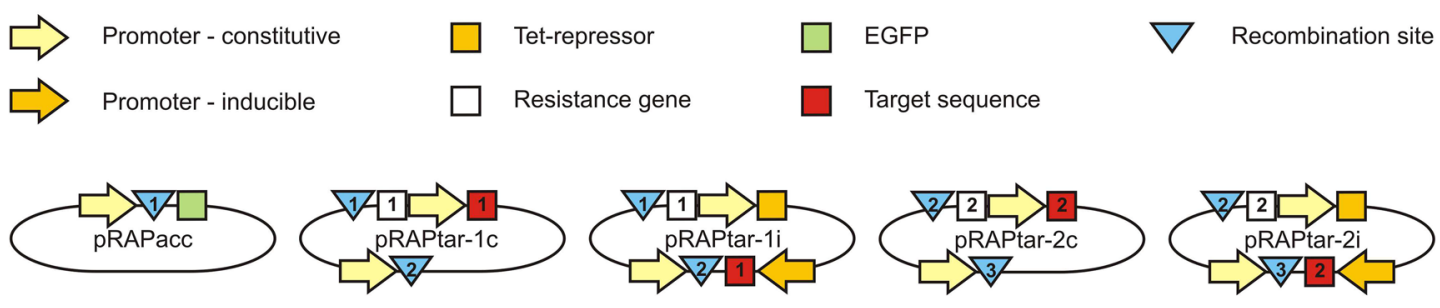

B

ISOGENIC DOUBLE RECOMBINANTS

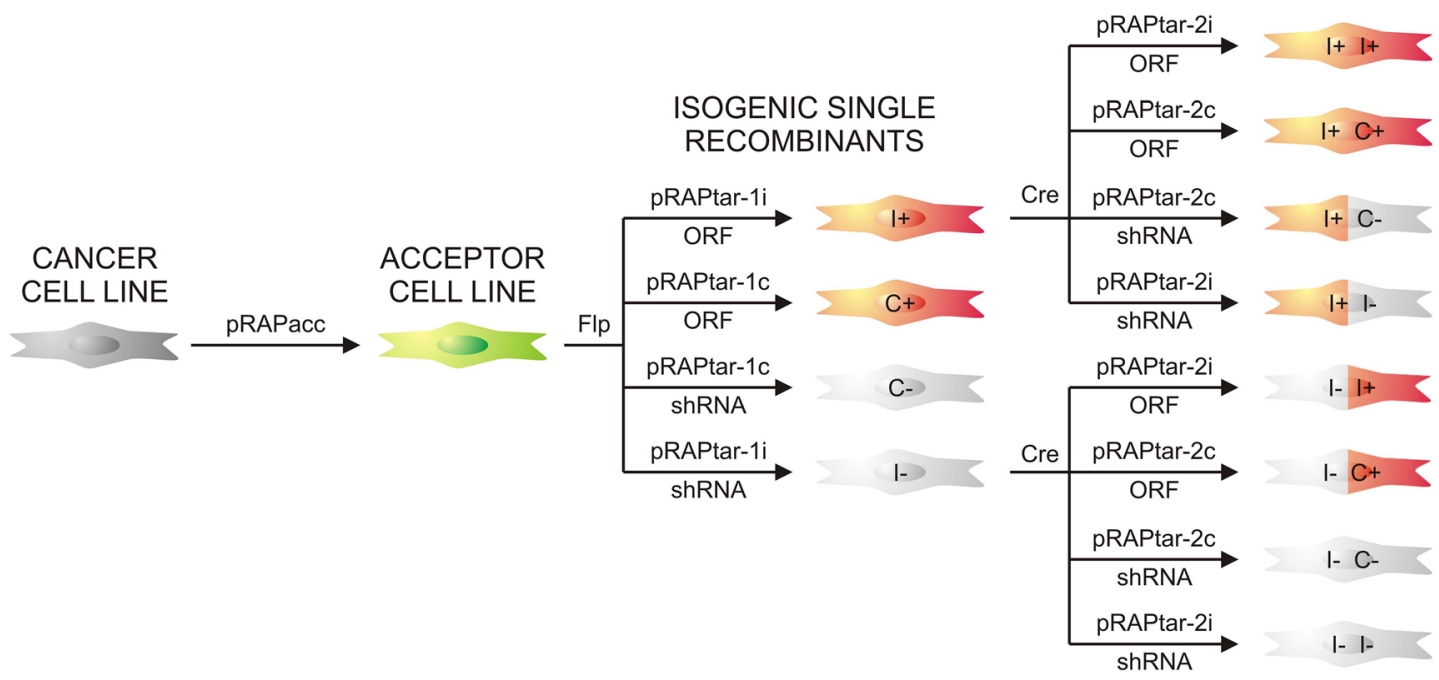

Figure 2: Schematic survey of the system. (A) Display of the vectors with their most relevant elements. Recombination sites are indicated by blue triangles (1: FRT-site; 2: lox-sites; 3: phiC31 attP site for later expansion). White squares depict resistance genes for selection of isogenic single recombinant cells (ISRs; 1: hygromycin resistance gene) and isogenic double recombinant cells (IDRs; 2: puromycin resistance gene). Red squares symbolize the inserted target sequence, which could be either a gene or a shRNA-coding cassette for knockdown (1: target sequence for first insertion via Flp-FRT; 2: target sequence for second insertion via Cre-lox). (B) Schematic survey of part of the permutations of traits that can be generated. Recombination-mediated insertion of a pRAPtar-1 vector in the ACL genome yields selectable ISRs that lack green fluorescence and display either dox-inducible (I) or constitutive (C) expression of the target sequence. ISRs with overexpression of an open reading frame (ORF) or short hairpin RNA-mediated silencing of a gene (shRNA) would show gain ("+") or loss of function ("-"). Consecutive Cre-mediated insertion of a pRAPtar-2 vector yields selectable IDRs with the desired combination of traits as exemplified for using the two inducible single recombinants. 
Table 1: Generation of acceptor cell lines

\begin{tabular}{|c|c|c|c|c|c|c|}
\hline Cell line & Type & $\begin{array}{l}\text { Stable } \\
\text { clones }\end{array}$ & $\begin{array}{c}\text { Single } \\
\text { integration }\end{array}$ & Rec. $+^{a}$ & Expr. $+^{b}$ & ACL Name \\
\hline Mewo & Melanoma & 42 & 13 & 4 & 0 & - \\
\hline SkMel28 & Melanoma & 20 & 4 & 3 & 0 & - \\
\hline A 375 & Melanoma & 32 & 7 & 4 & 3 & $\mathrm{~N} 103^{c}, \mathrm{~N}^{\circ} 04^{c}, \mathrm{~N} 120^{c}$ \\
\hline H1299 & Lung cancer & 48 & 6 & 6 & 1 & $\mathrm{~B} 5^{c}$ \\
\hline A549 & Lung cancer & 53 & 12 & 12 & 1 & $\mathrm{X} 12^{d}$ \\
\hline MCF-7 & Breast cancer & 42 & 6 & 2 & 1 & $\mathrm{~N} 107^{c}$ \\
\hline MDA-MB-231 & Breast cancer & 25 & 8 & 8 & 0 & - \\
\hline U87-MG & Brain cancer & 42 & 4 & 4 & 0 & - \\
\hline U138-MG & Brain cancer & 54 & 3 & 3 & 0 & - \\
\hline U251-MG & Brain cancer & 16 & 7 & 4 & 2 & $\mathrm{~L} 106^{c}, \mathrm{~L}^{e}$ \\
\hline Total & 10 & 374 & $70 / 374$ & $50 / 70$ & $8 / 50$ & $5 / 10$ cell lines \\
\hline Success rate & & & $19 \%$ & $71 \%$ & $16 \%$ & $50 \%$ \\
\hline
\end{tabular}

${ }^{a}$ capable of accepting pRAPtar-1 vector by site-specific recombination as judged by obtaining hygromycin-selectable cells lacking green fluorescence; ${ }^{b}$ capable of expressing target genes in an inducible fashion as judged by fluorescence microscopy and flow cytometry analysis with the HcRed reporter gene in pRAPtar-1i after dox induction; ${ }^{c}$ generated with pRAPacc2; ${ }^{d}$ generated with earlier variant of pRAPacc1 (pRAPacc1a) containing an additional TetR, which was nonfunctional after stable insertion; ${ }^{e}$ generated with pRAPacc1.

constitutively switched on (Table 1), as was determined by fluorescence microscopy.

We further analyzed the performance of the doxinducible expression vector. Consequently, we used the HcRed gene that was inserted in pRAPtar-1i via Flprecombinase for testing. Silencing and induction of red fluorescence was detected via microscopy and flow cytometry. The majority of the clones (42 out of 50; 84\%) either displayed lack of suppression in the absence of dox or lack of induction after dox addition (summarized in Table 1). The remaining eight ACLs covered five different cancer cell lines (Table 1, Figure 3A and 3B, Supplementary Figure 3A). For a single ACL-pRAPtar-1i clone per cancer cell line we further confirmed inducible HcRed expression quantitatively in response to increasing amounts of dox (Figure 3C, Supplementary Figure 3B). In conclusion, from 374 clones eight ACLs were isolated for the subsequent construction of clones with functional constitutive and inducible gene expression. For five out of 10 cancer cell lines, ACLs could be obtained that passed the described quality filters, corresponding to a $50 \%$ success rate.

\section{Construction of isogenic single and double recombinant cells}

To further test properties of the ACLs, we focused on A375-ACLN103 (melanoma) cells. Fluorescence microscopy and flow cytometry confirmed high and homogeneous expression after insertion of the HcRed gene via pRAPtar- $1 \mathrm{c}$ recombination and quantitatively inducible expression after insertion of the HcRed gene via pRAPtar-1i recombination (Figure 3A-3C). We next inserted the TP53 gene cloned in pRAPtar-1i into the ACL genome and isolated six independent EGFP-negative clones (TP53-ISRs).

Southern blot analyses confirmed TP53 insertion exclusively into the genomic location flagged by the FRT-site (Figure 3D and 3E). We also inserted CDKN1A in pRAPtar-1i and tested inducible expression of the gene alongside TP53 expression in one of the TP53ISRs. Both clones displayed tunable mRNA expression levels in response to different dox concentrations and showed highly comparable induction kinetics (Figure 3F). In conclusion, the data indicated that ISRs demonstrated uniform induced expression as expected from isogenic cells.

Finally, we tested the construction of inducible double recombinants (IDRs) suitable to express combinatorial traits via Cre-mediated recombination. To facilitate this we used the A375-ACLN103 ISRs with inducible HcRed expression, as described above, and a commercially available EGFP-shRNA fusion construct which targets the cellular $L M N A$ gene. The construct was cloned in pRAPtar-2i and -2c. Subsequently, IDRs were constructed which were expected to exhibit inducible 
HcRed fluorescence in conjunction with inducible or constitutive EGFP expression and parallel LMNA knockdown.

Resulting puromycin-resistant IDRs displayed the expected fluorescence patterns (Figure 4A and 4B). qRT-PCR of three individual IDRs for each configuration further suggested uniform performance with downregulation of $L M N A$ mRNA to 0.53 - to 0.49 fold for the IDRs with inducible EGFP-shRNA expression and 0.43- up to 0.16-fold for IDRs with constitutive EGFP-shRNA expression (Figure 4C). These results indicated that the system could be used efficiently to generate uniform isogenic cell lines with individual or combinatorial molecular traits.

\section{Construction and screening of an isogenic melanoma cell line library}

Our original objective was to develop a system for systematic functional analysis of large gene sets obtained from e.g. genome-wide sequencing studies reporting on recurrent mutations in tumor tissues [1-7]. To establish if our recombination system was able to analyze such large gene sets, we shuttled 108 genes including known tumor suppressors, oncogenes and randomly selected genes (Supplementary Table 2) into the pRAPtar-1i vector and subsequently inserted these into A375-ACLN103 melanoma cells. For $95 \%$ of the selected genes point mutations and/or copy number variations in malignant
A

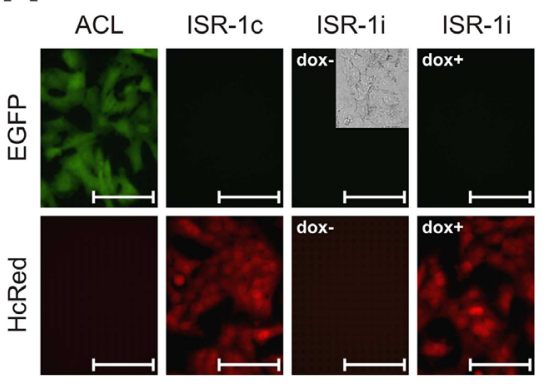

D

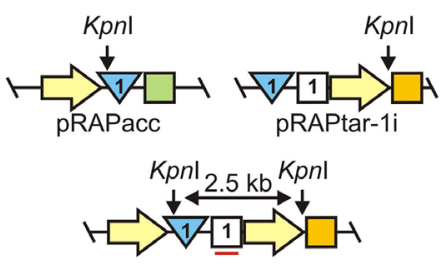

B

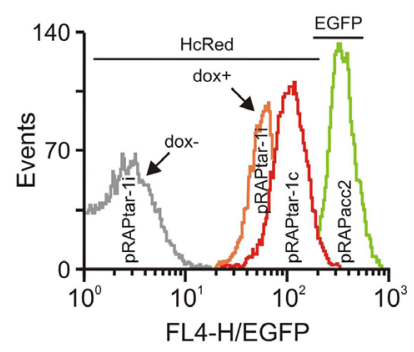

$\mathbf{E}$

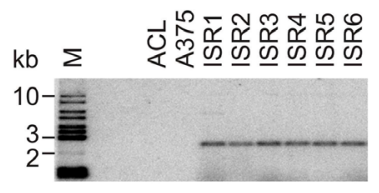

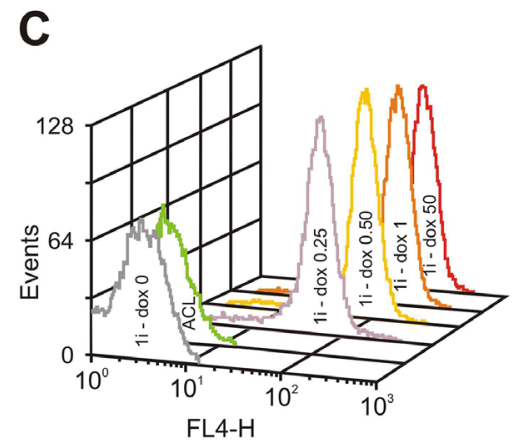

$\mathbf{F}$

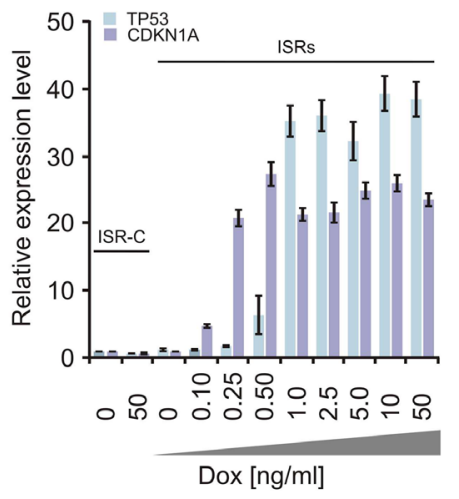

Figure 3: Construction of isogenic single recombinants. Analyses used A375-ACLN103 cells. (A) Fluorescence microscopy of acceptor cell line A375-ACLN103 (ACL) and isogenic single recombinants with insertion by recombination of constitutively (ISR-1c) and dox-inducibly (ISR-1i) expressed HcRed. The phase contrast inlay (cropped) is to demonstrate the presence of cells. For ISR-1i images were taken $48 \mathrm{~h}$ after induction without (dox-) or with (dox+) $50 \mathrm{ng} / \mathrm{ml}$ doxycycline. Scale bars: $100 \mu \mathrm{m}$. (B) Flow cytometry analyses of HcRed expression for the corresponding ISRs and of EGFP expression for A375-ACLN103. (C) Flow cytometry analyses of HcRed expression in response to different dox concentrations depicted in $\mathrm{ng} / \mathrm{ml}$ at the respective curve. The HcRed-negative ACL is included as negative control. (D) Configuration of pRAPacc inserted into the host cell genome (top left), part of pRAPtar-1i carrying the TP53 open reading frame (top right) and after recombination of pRAPtar-1i into the FRT-site in the host cell genome (bottom). Yellow arrow: promoter; blue triangle: FRT-site; green square: EGFP; white square: hygromycin resistance gene; orange square: Tet-repressor. Correct insertion into the genome-localized FRT-site would combine two KpnI restriction sites in such way that a new and unique 2.5 -kb restriction fragment emerges that can be detected with a radioactively labeled probe against the hygromycin resistance gene (indicated by the red line). (E) Southern blot analysis of KpnI-digested genomic DNA from six independent ISRs with insertion of TP53 cloned in pRAPtar-1i (ISR1-6), the A375-ACLN103 acceptor cell line used (ACL) and the original non-modified A375 cell line, probing the hygromycin resistance gene. M: size marker. (F) TP53 and CDKN1A were used to construct ISRs with pRAPtar-1i. Isogenic control recombinants (ISR-C) with insertion of the empty (i.e. ORF-deficient) pRAPtar-1i vector served as negative controls. Levels of mRNA expression were analyzed $48 \mathrm{~h}$ after induction with different dox concentrations by qRT-PCR. Error bars represent SEM. 
melanoma are reported according to the COSMIC database (http://cancer.sanger.ac.uk/cosmic) [19].

Transfection of A375-ACLN103 cells grown in two wells of a 6-well plate per gene was sufficient to yield at least three independent EGFP-negative ISR clones. Three clones per gene were consecutively pooled to minimize any potential random variation. Cells with insertion of the empty pRAPtar-1i vector served as isogenic controls (ISR-C), which allowed normalization for effects introduced by the vector system and/or by changes to the genomic insertion site. Subsequently, we analyzed changes in cell viability before and after induction of gene expression in a discovery screen. We identified 11 genes with significant growthsuppressive effects compared to the isogenic controls (Figure 5A). Many of these effects are in accordance with current literature. For example, A375 cells harbor wild type TP53, expressed at substantial levels, but display comparably low CDKN1A (p21) protein levels [20]. Accordingly, TP53 overexpression did not cause significant changes in cell viability, while CDKN1A overexpression caused strong growth suppression. $M Y C$ has been reported to cause $\mathrm{G} 2$ cell cycle arrest in cells with wild type TP53 [21], which is in accordance with the significant suppression mediated by $M Y C$ in the discovery screen. The tumor suppressor PTEN exerted a moderate but significant growth suppressive effect (Figure 5A).

We selected a set of 26 genes, including the nine most prominent growth suppressors, for an independent validation by construction and screening of ISRs generated with A375-ACLN120 cells (Supplementary Table 3). Southern blot data indicated a different genomic insertion site as compared to A375-ACLN103 cells (Supplementary Figure 2A and 2B) such that this independent approach was suitable to filter for effects on cell growth caused by the chromosomal location of the insertion site. The validation screen confirmed effects on growth for 25 out of 26 genes. Only DDX10 was not confirmed, leading to a $96 \%$ confirmation rate and a Pearson correlation coefficient of 0.87 (Figure 5B and 5C). In summary, this indicated that ISR libraries can be used efficiently to analyze large gene sets and to identify phenotypic effects in a robust fashion.

\section{Identification of a potential tumor suppressive network}

We selected a subset of the genes with confirmed growth suppressive effects for further analysis. First, we subjected the ISRs generated with A375ACLN103 to cell cycle analyses. CDKN1A, used as positive control, caused the expected G0/G1 arrest. Furthermore, the G2-arrest suggested in the literature for $M Y C$ overexpression in TP53 wild type cells was confirmed and accompanied by a significant increase of apoptotic cells (Figure 6A, Supplementary Figure 4). Among the top five growth-suppressing genes tested, STARD8 and DUSP6, a commonly known tumor suppressor [22, 23], arrested cells in G1/G0-phase, while MAPRE3, RPS6KA2 and EMD induced apoptosis (Figure 6A, Supplementary Figure 4). Apoptosisinducing effects were also confirmed in independent assays by quantifying inter-nucleosomal genomic DNA degradation (Figure 6B).
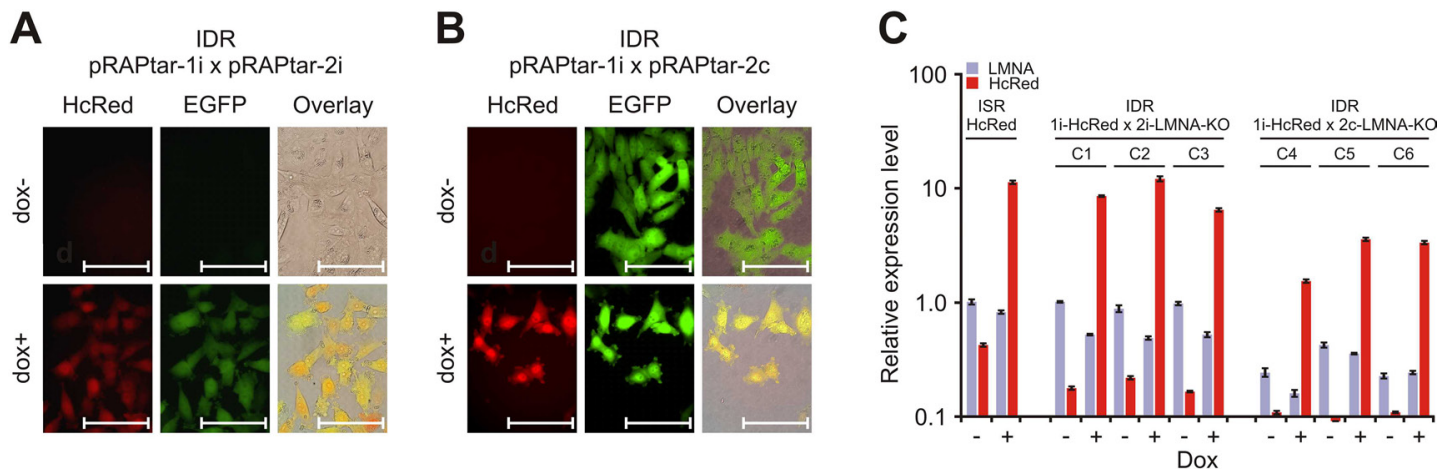

Figure 4: Construction of isogenic double recombinants. The ISR with insertion of dox-inducible HcRed was used to generate IDRs via Cre-lox mediated recombination with either (A) dox-inducible (pRAPtar-2i) or (B) constitutive expression (pRAPtar-2c) of a second sequence. The sequence comprised an emerald GFP (EGFP) reporter gene linked to a cassette for expression of an shRNA targeting the cellular $L M N A$ gene. (A) Fluorescence microscopy of IDRs with inducible EGFPshRNA cassette shows induction of both reporters $(2 \mu \mathrm{g} / \mathrm{ml}$ dox for maximum induction). Scale bars: $100 \mu \mathrm{m}$. (B) Fluorescence microscopy of IDRs with constitutive EGFP-shRNA cassette $48 \mathrm{~h}$ post induction with $2 \mu \mathrm{g} / \mathrm{ml}$ dox and without induction. Scale bars: $100 \mu \mathrm{m}$. (C) Quantification of knockdown and overexpression in IDRs. Three clones each (C1-C3 and C4-C6, respectively) were analyzed for knockdown of $L M N A$ and induction of HcRed mRNA expression by qRT-PCR. Values are referred to $L M N A$ levels in the ISR with HcRed insertion only (without induction). Error bars represent SEM. 
These five genes were further utilized to construct ISRs from ACLs of the other three cancer types, using the inducible vector pRAPtar-1i, to investigate if the observed growth suppressive effects were melanomaspecific. Tumor suppressive effects were confirmed for all five genes in at least one additional cancer type (Figure 6C). ISRs with EMD could not be constructed for the brain cancer U251-ACLL106, this was likely due to strong apoptotic effects exerted by low leaky expression levels in the absence of dox. Of note, in MCF7 breast cancer cells, STARD 8 had a growthpromoting effect as opposed to its tumor-suppressive function in melanoma and lung cancer.

GeneMANIA analysis (www.genemania.org) [24] further indicated that DUSP6, EMD, MAPRE3 and RPS6KA2, but not STARD8, are linked in a tumor suppressive network as defined by known genetic, pathway and/or physical interactions (Figure 6D). Taken together, the data confirmed tumor suppressive functions for the five genes, however, STARD 8 may function as context-specific tumor suppressor or oncogene. The unbiased screen identified a potential tumor suppressive network which may be relevant in various cancer types. However, these results have to be confirmed via functional studies.

\section{The tumor suppressor DUSP6 is a putative synthetic lethal target in melanoma}

Analyses in primary melanoma and melanoma cell lines indicated that MAPRE3 and EMD mRNA levels were not substantially changed compared to primary normal human epidermal melanocytes (NHEM). While STARD 8 levels were upregulated in primary tumors and decreased in cell lines (Figure 7A), RPS6KA2 levels were normal or decreased, however, DUSP6 mRNA expression was consistently elevated (Figure 7A).

Activating BRAF mutations, such as the common V600E mutation, result in increased MEK activation, which leads to ERK1/2 phosphorylation. PhosphoERK1/2 in turn activates downstream targets via phosphorylation, among these p90RSK3 which is coded by RPS6KA2. In this regulatory circuit, DUSP6 functions as tumor suppressor in limiting ERK1/2 activity via dephosphorylation (Figure 7B) [23, 25, 26]. In accordance with its role as an ERK1/2 downstream target, RPS6KA2

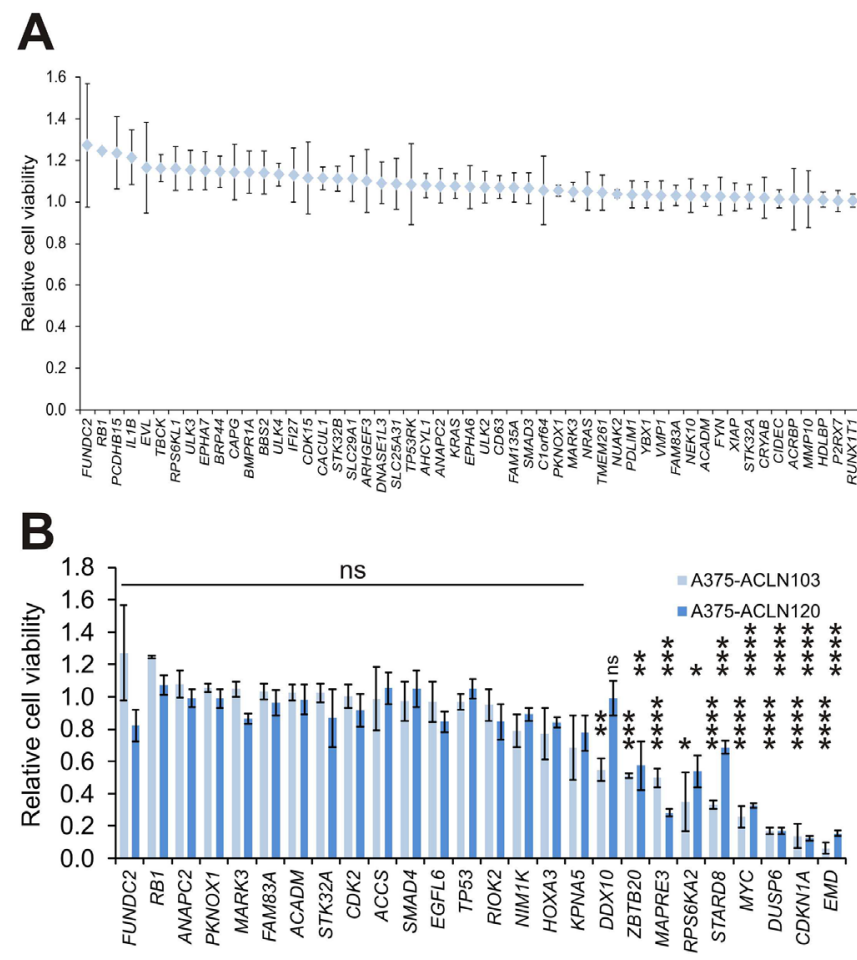

Figure 5: Screen of a melanoma isogenic single recombinant cell library. (A) A library of 108 A375-ACLN103-derived ISRs was generated and subjected to a cell viability scan as the primary (discovery) screen. Cell viability is displayed relative to ISRs with the empty expression plasmid (pRAPtar-1i) inserted (ISR-C). Eleven primary hits, including known cancer genes like TP53, CDKN1A, PTEN and $M Y C$, were identified. (B) Validation of a panel of 26 genes in independent ISRs generated with A375-ACLN120 cells. Data from primary screen is included for comparison. (C) Correlation plot of validation versus primary screen with Pearson correlation coefficient (PCC) of 0.87. Statistical significance was evaluated using two-tailed Student's t-tests and is indicated by *: $P<0.05$; **: $P<0.01$; ***: $P<0.001$; ****: $P<0.0001$. All error bars represent SEM. 
has been associated with oncogenic functions by various groups [27-29]. Here, our results indicated that increased p90RSK3 activity triggers apoptosis (Figure 6A and $6 \mathrm{~B})$, suggesting that p90RSK3 may also function as a tumor suppressor in specific scenarios. Survival analyses available for breast and lung cancer patients [30] supported this hypothesis as high expression of both DUSP6 and RPS6KA2 were associated with significantly improved survival in both cancer types (Figure 7C).

We therefore hypothesize that elevated DUSP6 levels in melanoma are one mechanism for compensating BRAF V600E hyperactivation, which might otherwise trigger apoptosis via ERK1/2 downstream targets. To investigate this, we performed an siRNA-mediated knockdown of DUSP6 in BRAF wild type melanoma. As expected for a tumor suppressor, the knockdown either promoted cell growth or did not exert any effect, while the same knockdown in BRAF V600E melanoma with high DUSP6 expression caused cell death via induction of apoptosis (Figure 7D-7G). This indicated inactivation of tumor suppressors, specifically DUSP6, as a counterintuitive, but conceivable, synthetic lethal therapeutic concept in a subset of melanomas.

\section{DISCUSSION}

Our present study was initiated to investigate how large gene sets, resulting from genome-wide cancer mutation screens, can be functionally analyzed with a high degree of efficiency and standardization. There is a continuously growing demand for such functional genomic approaches because large numbers of driver genes have been classified solely based on statistical analysis and bioinformatic filtering processes [1-7]. However, the vast majority of the identified genes and their mutations have unknown functions in general and in cancer in particular. Finally, as discussed below, the identification of oncogenes or tumor suppressors in one cancer (sub)type does not necessarily translate to other cancer (sub)types.

\section{A}

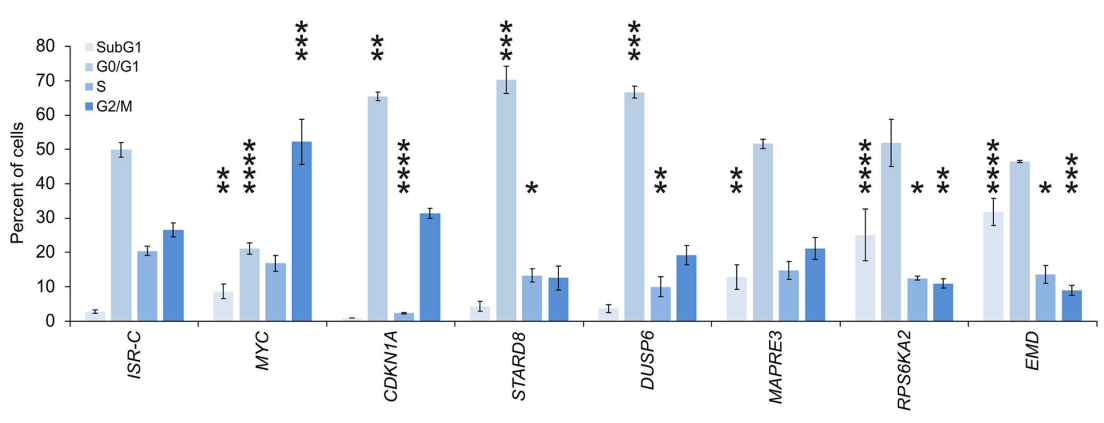

B
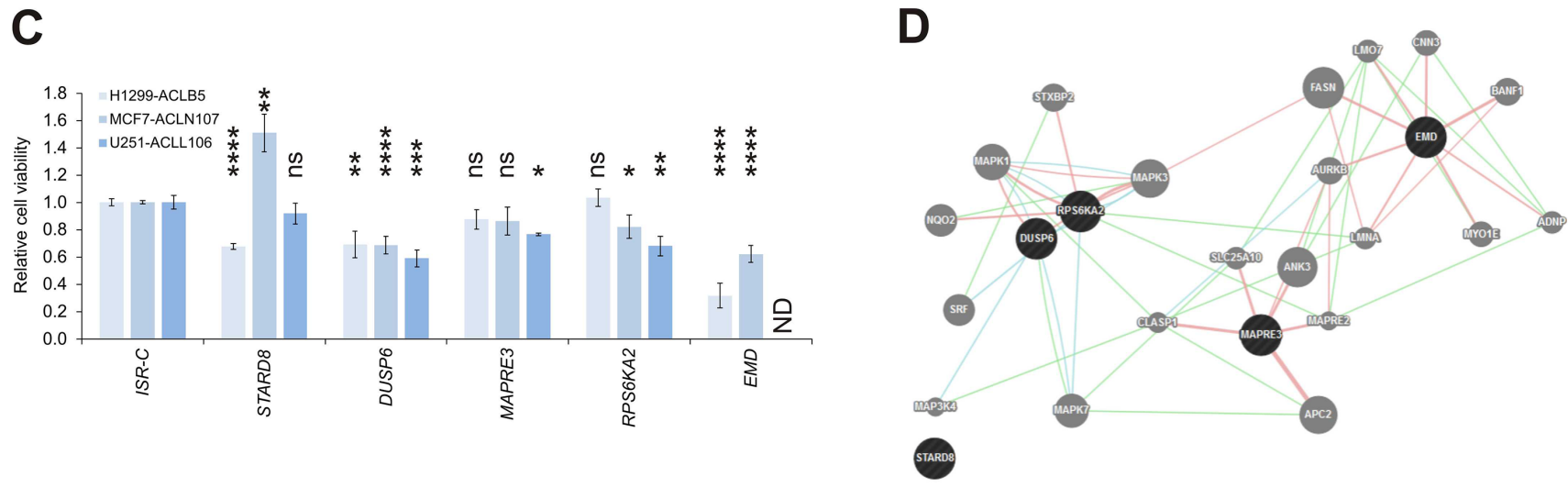

Figure 6: Identification of a tumor suppressive network. (A) Cell cycle distribution as mean of at least two independent experiments (background: A375-ACLN103). (B) Relative apoptosis activity as mean of two independent experiments (background: A375-ACLN103). (C) One ACL clone of each of the other three cancer backgrounds was used to create ISRs for the five genes and correspondingly matched negative controls (ISR-Cs). ISRs were subjected to cell viability analyses after induction with dox. The effect of EMD in U251-ACLL106 could not be determined (ND) because here no ISR could be obtained. (D) Interaction network suggested by GeneMANIA tool (www. genemania.org). Dark gray: query genes; light gray: interacting genes. Genetic, pathway and physical interactions are indicated by green, blue, and red lines, respectively. Statistical significance was evaluated using one-tailed Student's t-tests for the relative apoptosis activity and otherwise using two-tailed Student's t-tests and is indicated as *: $P<0.05$; **: $P<0.01 ; * * *: P<0.001 ; * * * *: P<0.0001$; ns: not significant. All error bars represent SEM. 
Several strategies for systematic functional analysis are based on currently available techniques. Among these are genome-editing techniques that allow for the introduction of genetic changes to obtain isogenic cells. While these techniques provide site-specific integration they may require the screening of hundreds of cell clones to identify corresponding cells carrying the desired knockdown or specific mutation [10-14]. We propose the construction of accepter cell lines (ACLs), which greatly simplifies the subsequent insertion of one or several genes of interest. We demonstrate that the first step to creating suitable ACLs experiences the same low efficacy as genome-editing. Even with an improved vector system, it required scanning of 374 clones to derive 8 suitable ACLs, corresponding to an efficacy of $2 \%$. However, the consecutive insertion of target genes into ACLs demonstrated a success rate of nearly $100 \%$.

Within the $>100$ constructed ISRs, only an isogenic U251 cell line for induced overexpression of EMD could not be generated, conceivably due to the strong apoptotic effects caused by the gene. Thus, the proposed strategy enables the efficient generation of permanent isogenic cell line libraries, which can successively be interrogated into various functional assays to analyze effects on e.g. proliferation, invasion/migration, apoptosis, or tumorsphere formation. We analyzed effects on
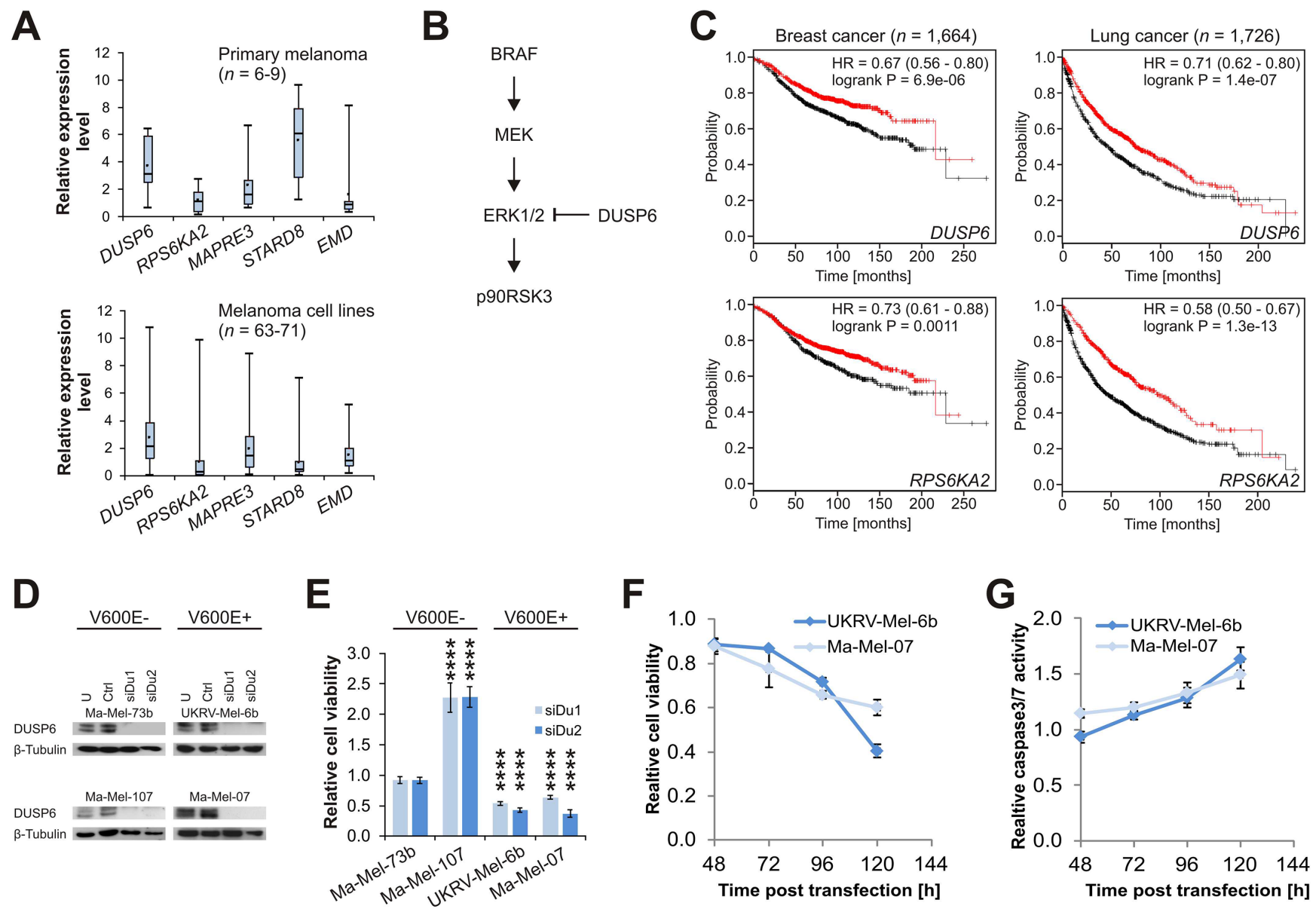

Figure 7: DUSP6 is a context-specific synthetic lethal target in melanoma. (A) mRNA expression levels for five genes in primary melanoma (top panel) and melanoma cell lines (bottom panel). Case numbers are provided in the diagrams and levels are normalized to the average of two independent samples of NHEM, which were set to 1.0 (not shown). Error bars represent minimum and maximum values. (B) Schematic extract from Ras/Raf/MEK/ERK signaling pathway. DUSP6 inhibits p90RSK3 (coded by RPS6KA2) activation via ERK1/2 dephosphorylation. (C) Kaplan Meier plots for luminal A breast cancer patients (left panels; relapse-free survival) and lung cancer patients (right panels; overall survival). Patients are split according to high (red curve) and low (black curve) expression. HR: hazard ratio with 95\% confidence interval. (D) Western blot analyses of siRNA-mediated DUSP6 knockdown in four selected melanoma cell lines with confirmed BRAF mutation status [43]. U: untreated; Ctrl: non-targeting control siRNA; siDu1 and siDu2: two DUSP6-targeting siRNAs. (E) Relative cell viability after DUSP6 knockdown referred to Ctrl. (F) Time course of relative cell viability in the two susceptible cell lines, and (G) corresponding Caspase-3/7 activity assessed in parallel and normalized to cell viability. Statistical significance was evaluated using two-tailed Student's t-tests and is indicated by *: $P<0.05 ; * *: P<0.01$; ***: $P<0.001$; ***: $P<0.0001$. All error bars represent SEM unless otherwise indicated. 
cell viability as a typical readout and achieved a $96 \%$ concordance rate between the discovery screen and the validation screen in an independent ACL derived from A375 melanoma cells.

As proof of concept, we constructed an isogenic melanoma cell line panel for a set of 108 genes, which were subsequently analyzed in a cell viability screen. We acknowledge that cell viability encompasses only one functional aspect among many that contribute to tumorigenesis. However, once established, the cell line libraries can be extensively studied using various additional functional assays.

Our results further demonstrated that five genes selected for their strong effect on cell viability also exerted effects in other cancer types. One of the five genes was STARD8 (also known as DLC3), which functions as a Rho-specific GTPase-activating protein involved in endocytic trafficking [31]. Its inactivation may prevent EGFR degradation and interfere with adherens junction integrity, in particular with E-cadherin function [31, 32]. One study reported a tumor suppressive role of STARD8, which is in accord with our results in A375 cells [33]. However, Durkin et al. observed indications for a tumor suppressive role of STARD 8 in MCF7 cells [33], whereas our results suggested a growth-promoting effect. The contrasting data could be a result of Durkin et al. using the longer DLC3 $\alpha$ transcript variant [33], while we used the alternatively spliced shorter DLC $3 \beta$ variant. MAPRE3 (also known as $E B 3$ or $E B F 3$ ) codes for a microtubule end-binding protein that stabilizes focal adhesions and has been demonstrated to trigger apoptosis in cancer types other than those analyzed here [34-36]. EMD codes for emerin, which is affected by mutations in X-linked EmeryDreifuss muscular dystrophy. While EMD-deficient fibroblasts were recently shown to proliferate abnormally [37], the gene has not yet been linked to cancer. No consistent pattern of changes in mRNA expression levels were observed for these three genes in melanoma, such that their putative role in this cancer type remains elusive.

We further analyzed DUSP6, which is a welldescribed tumor suppressor engaged in a regulatory loop with ERK1/2. DUSP6 counteracts Ras/Raf/MEK/ ERK signaling by ERK1/2 desphosphorylation [23, 26]. In our study, it exerted tumor suppressive functions in all four cancer types analyzed. Notably, we uncovered an unexpected opportunistic oncogenic role for DUSP6 that may involve downstream signaling via p90RSK3, which is activated by ERK1/2-mediated phosphorylation. Inactivation of p90RSK3 acts synergistically with EGFRinhibition, thus posing a potential synthetic lethal drug target for overcoming PI3K-inhibitor resistance in breast cancer $[27,28]$. Of note, RPS6KA2 was also determined to be a downstream target of BMI1 in glioblastoma stem cells [29]. These findings indicate a role as an oncogene. In contrast, Bignone et al. reported that RPS6KA2 is a tumor suppressor that triggers G1-arrest and apoptosis in ovarian cancer [38].
We also observed RPS6KA2-mediated apoptosis in our studies, which led us to investigate the knockdown effect of the upstream tumor suppressor DUSP6, which we expected to result in RPS6KA2 hyperactivation via ERK1/2. Our hypothesis led to the identification of DUSP6 as a potential synthetic lethal target in melanoma with BRAF V600E mutation and high expression of DUSP6, suggesting that, in certain scenarios, this tumor suppressor may serve as drug target. This counterintuitive proposition might be supported by recent findings that indicate less strict delineations between tumor suppressors and oncogenes. The concept of TP53 gain-of-function mutants has been revitalized and the functions of oncogenic TP53 are currently under intensive investigation [39-41]. Importantly, members of the DUSP protein family, including DUSP6, have recently been proposed as therapeutic targets for glioblastoma multiforme, where DUSP6 causes tumor-promoting effects and chemoresistance [42, 43].

A distinct advantage to the presented strategy is its support for studying combinatorial traits, e.g. by the overexpression of one target gene and the parallel knockdown of a second target gene. We demonstrated this by constructing IDRs with fluorescence reporter expression and a parallel LMNA knockdown via subsequent recombination of both target sequences into the ACL genome. Thus, the system can, in principle, be used for large combinatorial studies such as a systematic screen for synthetic lethal targets in cancer.

In conclusion, we demonstrate a robust and flexible strategy for the construction of isogenic cell line libraries and establish its applicability for systematically screening larger gene sets commonly recovered from genome-wide sequencing studies. The results of a systematic proof-ofconcept cell viability screen led to subsequent hypothesisbased experiments, which identified DUSP6 as contextspecific synthetic lethal target in melanomas with BRAF V600E mediated ERK1/2 activation.

\section{MATERIALS AND METHODS}

\section{Cell lines and patient samples}

Cell lines from Table 1 were obtained and cultivated according to the instructions from ATCC. Primary melanoma samples and patient-derived melanoma cell lines are part of the panel previously described [44]. All tumor samples and clinical data were collected with Institutional Review Board approval and patient's informed consent.

\section{Transfection of acceptor plasmids}

For comparison of pRAPacc $1 / 2$ to the pFRT/lacZeo, $2 \times 10^{6}$ cells were transfected with $4 \mu \mathrm{g}$ plasmid DNA in $100 \mu \mathrm{l}$ Nucleofector Solution (Lonza) via nucleofection, applying the conditions recommended by the supplier. 
Transfected cells were seeded into two wells of a 6-well plate per cell line and $24 \mathrm{~h}$ later zeocin or G418 selection was introduced at concentrations previously determined in titration experiments. After a further $48 \mathrm{~h}$, cells were transferred to $10 \mathrm{~cm}$ cell culture dishes and cultivated for 2 weeks for subsequent counting of reporter-positive clones. Cells transfected with pFRT/lacZeo were evaluated by conventional $\beta$-Gal staining, while cells transfected with pRAPacc $1 / 2$, were scored according to the number of green fluorescent colonies observed by fluorescence microscopy. Experiments were performed 2-3 times to calculate average values.

\section{Generation of isogenic recombinant cell lines}

Genes were shuttled into pRAPtar-1/2 vectors via the GATEWAY system (Invitrogen) according to the instructions of the supplier. The respective expression plasmid DNA was mixed at 1:5 ratio with either pOG44 for Flp-mediated recombination or pGK-Cre for Cremediated recombination. Consecutively, 1 x $10^{6}$ cells were seeded in 6-well plates and transfected with $5 \mu \mathrm{g}$ plasmid mixture using Lipofectamine according to manufacturer's instructions. Three days post transfection, the selection antibiotic was added (hygromycin for ISRs and puromycin for IDRs) according to individual optima determined for the ACLs. In the majority of the transfections at least three non-green fluorescent clones per 2 wells emerged, which were isolated and propagated separately until pooled for further analyses. For gene and cell line resources management, we utilized the OpenLabFramework software [45].

\section{Southern blot analyses}

Southern blot analyses were performed to identify ACLs with single integration and to confirm single insertion into the authentic locus for selected recombinants. For single integration $10 \mu \mathrm{g}$ genomic DNA was digested with PstI and for single insertion $15 \mu \mathrm{g}$ genomic DNA was digested with $K p n$ I, followed by gel electrophoresis on $1.2 \%$ agarose gels and conventional Southern blotting. Standard random hexamer-based radioactive labeling was applied to generate an $E G F P$-specific probe for analyses of ACLs and a probe targeting the hygromycin resistance gene for analyses of TP53-ISRs.

\section{Knockdown constructs}

We utilized the cassette of the BLOCK-iT ${ }^{\mathrm{TM}}$ Pol II miR-LMNA Validated miRNA Control Vector (Thermo Fisher Scientific), where the $L M N A$-targeting shRNA is cloned behind emerald GFP (EGFP). The insert was shuttled into pRAPtar-2i and $-2 c$ vectors, which consecutively were co-transfected with pGK-Cre plasmid into A375-ACLN103 ISR cells already carrying the inducible HcRed reporter in the first site. The HcRed ISR cells served as reference point for comparison in these analyses. Because use of pRAPtar- $2 \mathrm{i}$ inserts a second Tetrepressor and the two CMV promoters on pRAP-tar-1 and pRAPtar-2 might compete for each other, a higher dox concentration, arbitrarily set to $2 \mu \mathrm{g} / \mathrm{ml}$, was used for these experiments.

\section{Fluorescence microscopy}

Images of fluorescent cell lines were taken at 60 $\mathrm{x}$ magnification (scale bars provided in figures) with an Olympus IX71 microscope, using the filter sets U-MNIBA3 (green fluorescence) and U-MWU2 (red fluorescence) and the Cell soft pro software (Olympus) at uniform exposure times $500 \mathrm{~ms}$ for green and 1000 $\mathrm{ms}$ for red fluorescence. Image acquisition of IDRs in Figure $3 \mathrm{~B}$ was performed by using the automated contrast enhancement of the software due to weaker HcRed fluorescence in IDRs.

\section{Quantitative reverse transcription polymerase chain reaction}

For quantitative reverse transcription polymerase chain reaction (qRT-PCR) total RNA was purified using TRIzol reagent (Invitrogen), DNAse treated, and subjected to oligo-dT-primed reverse transcription according to standard protocols. Analyses were performed in triplicate wells with $10 \mathrm{ng}$ cDNA, using Human $A C T B$ and/or GAPDH Endogenous Control assays (Applied Biosystems) as references for normalization. The PCR was performed using a 7500 Real-Time PCR System (Applied Biosystems) under the following conditions: $60{ }^{\circ} \mathrm{C}$ for 15 min $\left(1\right.$ cycle) and $95^{\circ} \mathrm{C}$ for $15 \mathrm{sec}, 60^{\circ} \mathrm{C}$ for $1 \mathrm{~min}(40$ cycles). Data was analyzed using qbasePLUS evaluation software (Biogazelle). The following gene-specific assays (Applied Biosystems) were used: Hs99999147_m1 for TP53, Hs00355782_m1 for CDKN1A, Hs00153462_m1 for $L M N A$, Hs00169257_m1 for DUSP6, and a custommade assay was used for $\bar{H} c$ Red mRNA detection (forward primer: 5'-GGAGAGAACCACCACCTACGA-3'; reverse primer: 5'-CCTCCAGGCTGGTGTCC-3'; labeled probe: FAM-5'-ACGGCGGCATCCTGA-3'-NFQ).

\section{Flow cytometry}

For flow cytometric analyses, cells were trypsinized to a single cell suspension, centrifuged (270 g for $5 \mathrm{~min}$ ), resuspended in Hanks Balanced Salt Solution (HBSS) and stored on ice until analyzed with a FACSCalibur flow cytometer (Becton Dickinson). Cell debris and dead cells were excluded from the analyses via forward and side scatter parameters. EGFP was detected at $488 \mathrm{~nm}$ in the FL1 channel, while HcRed was detected at $640 \mathrm{~nm}$ in the FL4 channel. Per analysis 10,000 cells were evaluated. HcRed levels were analyzed after $48 \mathrm{~h}$ with induction by various dox-concentrations. 
For cell cycle analyses, we incubated the cells for 4 days in the presence of $50 \mathrm{ng} / \mathrm{ml}$ dox. The cells (about $5 \times 10^{5}$ cells) were then trypsinized, gently pelleted by centrifugation, and fixed with methanol for $6 \mathrm{~h}$ at -20 ${ }^{\circ} \mathrm{C}$. After removal of methanol, cells were resuspended in 7-aminoactinomycin D (7AAD) solution $(5 \mu \mathrm{g} / \mathrm{ml}$ $7 \mathrm{AAD}, 1 \mathrm{mg} / \mathrm{ml}$ RNase A in PBS) and incubated for 30 min at $37{ }^{\circ} \mathrm{C}$ followed by $90 \mathrm{~min}$ at $4{ }^{\circ} \mathrm{C}$. Fluorescence was evaluated as described above (detection at $650 \mathrm{~nm}$; FL3 channel).

\section{Cell viability assays}

We seeded 1,000 cells per well in 96-well plates and determined cell viability after $5 \mathrm{~d}$ incubation by addition of $20 \mu \mathrm{l}$ CellTiter-Blue reagent (Promega) per well. After $3 \mathrm{~h}$ incubation, fluorescence was measured at 550/610 $\mathrm{nm}$ in a Fusion Fluorometer (Packard Biosciences). Wells containing medium but no cells and processed in parallel were used for blank subtraction. To determine relative cell viability robustly, we first calculated relative viability of ISR cells without dox addition and with addition of $50 \mathrm{ng} / \mathrm{ml}$ dox relative to two independent empty vector control ISRs (ISR-C) processed in parallel. We then calculated the ratio of dox+/dox- cell viability, which should normalize for all factors contributed by vector components and/or inherent random variation among ISRs. Experiments were performed at least three times in triplicate. In the primary screen, only ISRs, which displayed a $20 \%$ or more change in cell viability were tested for statistical significance against isogenic controls.

\section{Apoptosis assays}

Relative apoptosis activity was determined using the Cell Death Detection ELISAPlus Kit (Roche). In brief, $10^{4}$ cells per well were seeded in 12 -well plates and cells were induced with $50 \mathrm{ng} / \mathrm{ml}$ dox $24 \mathrm{~h}$ post seeding. Determination of apoptosis activity followed $48 \mathrm{~h}$ post induction according to the instructions of the supplier. After subtraction of blank (medium-only) values, relative apoptosis activity was calculated normalized to an isogenic negative control cell line with the empty vector construct inserted (ISR-C).

Caspase-3/7 activity after DUSP6 knockdown was determined using the Apo-ONE Homogeneous Caspase-3/7 assay according to the protocol of the provider (Promega) and the fluorescence signal was detected at the wavelengths $485 / 535 \mathrm{~nm}$ with a Victor3 multi-label counter (PerkinElmer). The Caspase signal was normalized to the relative cell number analyzed in parallel using the fluorometric CellTiter-Blue reagent (Promega) as described above and finally referred to the values obtained for the non-targeting negative siRNA control (see below).

\section{DUSP6 knockdown}

For DUSP6 knockdown, cells were transfected with $25 \mathrm{nM}$ of siDul (sense: 5 -GUGCAACAGACUCGGAUGGUAtt-3`; anti-sense: 5 '-UACCAUCCGAGUCUGUUGCACtt-3`), siDu2 (sense: 5'-AGCUCAAUCUGUCGAUGAAtt-3`; antisense: 5'-UUCAUCGACAGAUUGAGCUtc-3'), or the non-targeting AllStars negative control siRNA (Qiagen), respectively, using the Lipofectamine RNAiMAX transfection reagent (Invitrogen) according to manufacturer's instructions. Transfection experiments were performed at least three times in triplicate in 24-well format using 12,500 cells per well. The medium was replaced $24 \mathrm{~h}$ post transfection and cells were cultured for an additional $48 \mathrm{~h}$ for protein extraction or another $96 \mathrm{~h}$ for cell viability and apoptosis assays.

\section{Western blot analyses}

To confirm the knockdown of DUSP6, total protein was harvested with RIPA buffer $48 \mathrm{~h}$ post siRNA transfection. Proteins $(20 \mu \mathrm{g}$ per sample) were separated by SDS-PAGE via an $8 \%$ Precise protein gel (Life Technologies) and blotted onto a Immobilon-P transfer membrane (Millipore). Detection of DUSP6 was performed using mouse monoclonal antibody (1:1000; Abcam ab54940) and HRP-conjugated rabbit antimouse IgG $(\mathrm{H}+\mathrm{L})$ secondary antibody (1:5000; Jackson Immunoresearch 315-035-003), and finally visualized with SuperSignal West Dura Extended Duration Substrate (Life Technologies). The antibody was afterwards removed from the membrane with $10 \mathrm{M}$ urea, $45 \mathrm{mM}$ SDS followed by washing steps with $50 \%$ ethanol, $10 \%$ acetic acid. Consecutively, the membrane was re-probed with a mouse monoclonal anti-beta tubulin antibody (1:1000; Abcam $\mathrm{ab} 7792$ ) and the same secondary antibody as before to confirm equal loading amounts of protein lysate.

\section{Abbreviations}

ACL, acceptor cell line; Cas9, CRISPR-associated protein-9 nuclease; CRISPR, Clustered regularlyinterspaced short palindromic repeats; Flp, flippase; FRT, flippase recognition target; IDR, isogenic double recombinant cell; ISR, isogenic single recombinant cell; ISR-C, isogenic single recombinant cell negative control; NGS, next-generation sequencing; NHEM, primary normal human epidermal melanocytes; shRNA, short hairpin RNA; siRNA, short interfering RNA; TALEN, Transcription Activator-Like Effector Nuclease

\section{ACKNOWLEDGMENTS}

We would like to thank Ewald Münstermann, Angelika Wörner and Kai Wunderlich for technical 
assistance and support in cloning. We would further like to thank Linda Harkness for revising the manuscript.

\section{CONFLICTS OF INTEREST}

The authors declare no competing interests.

\section{GRANT SUPPORT}

The work was supported by the NGFN Plus program of the German Federal Ministry of Education and Research (BMBF; IG-MUTANOM; Grant 01GS08105; J.M.), the Lundbeck Foundation (Grant NanoCAN; J.M.), and the Rektorspuljen SDU2020 Program (Grant: DAWN2020; J.M.).

\section{REFERENCES}

1. Sjöblom T, Jones S, Wood LD, Parsons DW, Lin J, Barber TD, Mandelker D, Leary RJ, Ptak J, Silliman N, Szabo S, Buckhaults P, Farrell C, et al. The consensus coding sequences of human breast and colorectal cancers. Science. 2006; 314:268-274.

2. Wood LD, Parsons DW, Jones S, Lin J, Sjöblom T, Leary RJ, Shen D, Boca SM, Barber T, Ptak J, Silliman N, Szabo $\mathrm{S}$, Dezso Z, et al. The genomic landscapes of human breast and colorectal cancers. Science. 2007; 318:1108-1113.

3. Shah SP, Roth A, Goya R, Oloumi A, Ha G, Zhao Y, Turashvili G, Ding J, Tse K, Haffari G, Bashashati A, Prentice LM, Khattra J, et al. The clonal and mutational evolution spectrum of primary triple-negative breast cancers. Nature. 2012; 486:395-399.

4. Nikolaev SI, Rimoldi D, Iseli C, Valsesia A, Robyr D, Gehrig C, Harshman K, Guipponi M, Bukach O, Zoete V, Michielin O, Muehlethaler K, Speiser D, et al. Exome sequencing identifies recurrent somatic MAP2K1 and MAP2K2 mutations in melanoma. Nat. Genet. 2011; 44:133-139.

5. Stark MS, Woods SL, Gartside MG, Bonazzi VF, DuttonRegester K, Aoude LG, Chow D, Sereduk C, Niemi NM, Tang N, Ellis JJ, Reid J, Zismann V, et al. Frequent somatic mutations in MAP3K5 and MAP3K9 in metastatic melanoma identified by exome sequencing. Nat. Genet. 2011; 44:165-169.

6. Wei X, Walia V, Lin JC, Teer JK, Prickett TD, Gartner J, Davis S, NISC Comparative Sequencing Program, StemkeHale K, Davies MA, Gershenwald JE, Robinson W, Robinson S, et al. Exome sequencing identifies GRIN2A as frequently mutated in melanoma. Nat. Genet. 2011; 43:442-446.

7. Berger MF, Hodis E, Heffernan TP, Deribe YL, Lawrence MS, Protopopov A, Ivanova E, Watson IR, Nickerson E, Ghosh P, Zhang H, Zeid R, Ren X, et al. Melanoma genome sequencing reveals frequent PREX2 mutations. Nature. 2012; 485:502-506.
8. Farmer H, McCabe N, Lord CJ, Tutt AN, Johnson DA, Richardson TB, Santarosa M, Dillon KJ, Hickson I, Knights C, Martin NM, Jackson SP, Smith GC, et al. Targeting the DNA repair defect in BRCA mutant cells as a therapeutic strategy. Nature. 2005; 434:917-921.

9. Naldini L, Blömer U, Gallay P, Ory D, Mulligan R, Gage FH, Verma IM, Trono D. In vivo gene delivery and stable transduction of nondividing cells by a lentiviral vector. Science.1996; 272:263-267.

10. Hockemeyer D, Wang H, Kiani S, Lai CS, Gao Q, Cassady JP, Cost GJ, Zhang L, Santiago Y, Miller JC, Zeitler B, Cherone JM, Meng X, et al. Genetic engineering of human pluripotent cells using TALE nucleases. Nat. Biotechnol. 2011; 29:731-734.

11. Soldner F, Laganière J, Cheng AW, Hockemeyer D, Gao Q, Alagappan R, Khurana V, Golbe LI, Myers RH, Lindquist S, Zhang L, Guschin D, Fong LK, et al. Generation of isogenic pluripotent stem cells differing exclusively at two early onset Parkinson point mutations. Cell. 2011; 146:318-331.

12. Ding Q, Lee YK, Schaefer EA, Peters DT, Veres A, Kim K, Kuperwasser N, Motola DL, Meissner TB, Hendriks WT, Trevisan M, Gupta RM, Moisan A, et al. A TALEN genome-editing system for generating human stem cellbased disease models. Cell Stem Cell. 2013; 12:238-251.

13. Gaj T, Gersbach CA, Barbas CF 3rd. ZFN, TALEN, and CRISPR/Cas-based methods for genome engineering. Trends Biotechnol. 2013; 31:397-405.

14. Hsu PD, Scott DA, Weinstein JA, Ran FA, Konermann S, Agarwala V, Li Y, Fine EJ, Wu X, Shalem O, Cradick TJ, Marraffini LA, Bao G, et al. DNA targeting specificity of RNA-guided Cas9 nucleases. Nat. Biotechnol. 2013; 31:827-832.

15. Senecoff JF, Bruckner RC, Cox MM. The FLP recombinase of the yeast 2-micron plasmid: characterization of its recombination site. Proc. Natl. Acad. Sci. USA. 1985; $82: 7270-7274$.

16. Zhang Z, Lutz B. Cre recombinase-mediated inversion using lox66 and lox71: method to introduce conditional point mutations into the CREB-binding protein. Nucleic Acids Res. 2002; 30:e90.

17. Soriano P. Generalized lacZ expression with the ROSA26 Cre reporter strain. Nat. Genet. 1999; 21:70-71.

18. Kuhstoss S, Rao RN. Analysis of the integration function of the streptomycete bacteriophage phi C31. J. Mol. Biol. 1991; 222:897-908.

19. Forbes SA, Beare D, Gunasekaran P, Leung K, Bindal N, Boutselakis H, Ding M, Bamford S, Cole C, Ward S, Kok CY, Jia M, De T, et al. Nucleic Acids Res. 2015; 43:D805-11.

20. Haapajärvi T, Pitkänen K, Laiho M. Human melanoma cell line UV responses show independency of p53 function. Cell Growth Differ. 1999; 10:163-171.

21. Felsher DW, Zetterberg A, Zhu J, Tlsty T, Bishop JM. Overexpression of MYC causes p53-dependent G2 arrest of normal fibroblasts. Proc. Natl. Acad. Sci. USA. 2000; 97:10544-10548. 
22. Wong VC, Chen H, Ko JM, Chan KW, Chan YP, Law S, Chua D, Kwong DL, Lung HL, Srivastava G, Tang JC, Tsao SW, Zabarovsky ER, et al. Tumor suppressor dualspecificity phosphatase 6 (DUSP6) impairs cell invasion and epithelial-mesenchymal transition (EMT)-associated phenotype. Int. J. Cancer. 2012; 130:83-95.

23. Zhang H, Chi Y, Gao K, Zhang X, Yao J. p53 proteinmediated up-regulation of MAP kinase phosphatase 3 (MKP-3) contributes to the establishment of the cellular senescent phenotype through dephosphorylation of extracellular signal-regulated kinase 1/2 (ERK1/2). J. Biol. Chem. 2015; 290:1129-1140.

24. Mostafavi S, Ray D, Warde-Farley D, Grouios C, Morris Q. GeneMANIA: a real-time multiple association network integration algorithm for predicting gene function. Genome Biol. 2008; 9:S4.

25. McCubrey JA, Steelman LS, Chappell WH, Abrams SL, Wong EW, Chang F, Lehmann B, Terrian DM, Milella M, Tafuri A, Stivala F, Libra M, Basecke J, et al. Roles of the Raf/MEK/ERK pathway in cell growth, malignant transformation and drug resistance. Biochim. Biophys. Acta. 2007; 1773:1263-1284.

26. Owens DM, Keyse SM. Differential regulation of MAP kinase signalling by dual-specificity protein phosphatases. Oncogene. 2007; 26:3203-3213.

27. Milosevic N, Kühnemuth B, Mühlberg L, Ripka S, Griesmann H, Lölkes C, Buchholz M, Aust D, Pilarsky C, Krug S, Gress T, Michl P. Synthetic lethality screen identifies RPS6KA2 as modifier of epidermal growth factor receptor activity in pancreatic cancer. Neoplasia. 2013; 15:1354-1362.

28. Serra V, Eichhorn PJ, García-García C, Ibrahim YH, Prudkin L, Sánchez G, Rodríguez O, Antón P, Parra JL, Marlow S, Scaltriti M, Pérez-Garcia J, Prat A, et al. RSK3/4 mediate resistance to PI3K pathway inhibitors in breast cancer. J. Clin. Invest. 2013; 123:2551-2563.

29. Baxter PA, Lin Q, Mao H, Kogiso M, Zhao X, Liu Z, Huang Y, Voicu H, Gurusiddappa S, Su JM, Adesina AM, Perlaky L, Dauser RC, et al. Silencing BMI1 eliminates tumor formation of pediatric glioma CD133+ cells not by affecting known targets but by down-regulating a novel set of core genes. Acta Neuropathol. Commun. 2014; 2:160.

30. Gyorffy B, Surowiak P, Budczies J, Lanczky A. Online survival analysis software to assess the prognostic value of biomarkers using transcriptomic data in non-small-cell lung cancer. PLoS One. 2013; 8:e82241.

31. Braun AC, Hendrick J, Eisler SA, Schmid S, Hausser A, Olayioye MA. The Rho-specific GAP protein DLC3 coordinates endocytic membrane trafficking. J. Cell Sci. 2015; 128:1386-1399.

32. Holeiter G, Bischoff A, Braun AC, Huck B, Erlmann P, Schmid S, Herr R, Brummer T, Olayioye MA. The RhoGAP protein Deleted in Liver Cancer 3 (DLC3) is essential for adherens junctions integrity. Oncogenesis. 2012; 1:e13.

33. Durkin ME, Ullmannova V, Guan M, Popescu NC. Deleted in liver cancer 3 (DLC-3), a novel Rho GTPase-activating protein, is downregulated in cancer and inhibits tumor cell growth. Oncogene. 2007; 26:4580-4589.

34. Zhao LY, Niu Y, Santiago A, Liu J, Albert SH, Robertson $\mathrm{KD}$, Liao D. An EBF3-mediated transcriptional program that induces cell cycle arrest and apoptosis. Cancer Res. 2006; 66:9445-9452.

35. Bennett KL, Romigh T, Eng C. Disruption of transforming growth factor-beta signaling by five frequently methylated genes leads to head and neck squamous cell carcinoma pathogenesis. Cancer Res. 2009; 69:9301-9305.

36. Ferreira JG, Pereira AJ, Akhmanova A, Maiato H. Aurora B spatially regulates EB3 phosphorylation to coordinate daughter cell adhesion with cytokinesis. J. Cell Biol. 2013; 201:709-724.

37. Meinke P, Schneiderat P, Srsen V, Korfali N, Le Thanh P, Cowan GJ, Cavanagh DR, Wehnert M, Schirmer EC, Walter MC. Abnormal proliferation and spontaneous differentiation of myoblasts from a symptomatic female carrier of X-linked Emery-Dreifuss muscular dystrophy. Neuromuscul. Disord. 2015; 25:127-136.

38. Bignone PA, Lee KY, Liu Y, Emilion G, Finch J, Soosay AE, Charnock FM, Beck S, Dunham I, Mungall AJ, Ganesan TS. RPS6KA2, a putative tumour suppressor gene at 6 q27 in sporadic epithelial ovarian cancer. Oncogene. 2007; 26:683-700.

39. Adorno M, Cordenonsi M, Montagner M, Dupont S, Wong C, Hann B, Solari A, Bobisse S, Rondina MB, Guzzardo V. A Mutant-p53/Smad complex opposes p63 to empower TGFbeta-induced metastasis. Cell. 2009; 137:87-98.

40. Muller PA, Caswell PT, Doyle B, Iwanicki MP, Tan EH, Karim S, Lukashchuk N, Gillespie DA, Ludwig RL, Gosselin P. Mutant p53 drives invasion by promoting integrin recycling. Cell. 2009; 139:1327-1341.

41. Kollareddy M, Dimitrova E, Vallabhaneni KC, Chan A, Le T, Chauhan KM, Carrero ZI, Ramakrishnan G, Watabe K, Haupt Y, Haupt S, Pochampally R, Boss GR, et al. Regulation of nucleotide metabolism by mutant p53 contributes to its gain-of-function activities. Nat. Commun. 2015; 6:7389.

42. Messina S, Frati L, Leonetti C, Zuchegna C, Di Zazzo E, Calogero A, Porcellini A. Dual-specificity phosphatase DUSP6 has tumor-promoting properties in human glioblastomas. Oncogene. 2011; 30:3813-3820.

43. Prabhakar S, Asuthkar S, Lee W, Chigurupati S, Zakharian E, Tsung AJ, Velpula KK. Targeting DUSPs in glioblastomas - wielding a double-edged sword? Cell Biol. Int. 2014; 38:145-153.

44. Ugurel S, Thirumaran RK, Bloethner S, Gast A, Sucker A, Mueller-Berghaus J, Rittgen W, Hemminki K, Becker JC, Kumar R, Schadendorf D. B-RAF and N-RAS mutations are preserved during short time in vitro propagation and differentially impact prognosis. PLoS One. 2007; 2:e236.

45. List M, Schmidt S, Trojnar J, Thomas J, Thomassen M, Kruse TA, Tan Q, Baumbach J, Mollenhauer J. Efficient sample tracking with OpenLabFramework. Sci. Rep. 2014; $4: 4278$. 